\title{
La suspensión del derecho a sufragio de las personas privadas de libertad como un acto de discriminación
}

\author{
The suspension of the right to vote as an act of discrimination \\ against persons deprived of their liberty
}

\author{
Karl-Andreas Müller GuZMÁN \\ Universidad Santo Tomás, Chile
}

Evelyn Vicencio Rojas

Universidad Santo Tomás, Chile

\begin{abstract}
RESUMEN En este trabajo se desarrollan tanto las razones que justifican como aquellas que rechazan la pérdida del derecho de sufragio a quien se encuentre privado de libertad. Asimismo, se explica la antinomia que existe entre el artículo 16 número 2 de la Constitución que consagra la suspensión del derecho de sufragio a la persona acusada por delito que merezca pena aflictiva o por delito que la ley califique como conducta terrorista, y lo dispuesto en el artículo 23 número 2 de la Convención Americana de Derechos $\mathrm{Hu}$ manos que permite limitar tal derecho respecto de personas condenadas por juez competente en proceso penal. Esta situación, a su vez, puede generar responsabilidad internacional del Estado.
\end{abstract}

PALABRAS CLAVE Derecho de sufragio, discriminación, responsabilidad internacional.

ABSTRACT In this work, both the reasons that justify and those that reject the loss of the right to vote to those who are deprived of their liberty are developed. It also explains the antinomy that exists between article 16 number 2 of the Constitution that enshrines the suspension of the right to vote for the accused person for a crime that deserves afflictive penalty or for a crime that the law qualifies as terrorist conduct, and the provisions in the Article 23 (2) of the American Convention on Human Rights, which makes it possible to limit this right to persons convicted by a competent judge in criminal proceedings. This situation, in turn, can generate international liability of the State.

KEYWORDS Right to vote, discrimination, international liability. 


\section{Introducción}

En Chile, como en otros Estados, algunas personas privadas de libertad no pueden ejercer su derecho de sufragio. Se puede apreciar la gravedad de esta sanción si se tiene presente el contenido del derecho que eventualmente se puede afectar, esto es:

el libre ejercicio de participación ciudadana en las decisiones colectivas y democráticas para la elección de candidatos y autoridades, para la determinación, vinculante o no, de la voluntad en un acto jurídico y para la reivindicación de la soberanía popular en los casos que la Constitución lo determine (García, Contreras y Placencia, 2014: 361).

Esta sanción podrá aplicarse de manera temporal, caso en el cual se habla de una suspensión del derecho, o bien, dicha sanción podrá ser consecuencia de una «situación más grave y definitiva» (Cea Egaña, 2002: 330), en cuyo caso se hablará de una privación del derecho de sufragio. En este trabajo se analizarán las diversas razones que justifican tanto la privación como la suspensión de este derecho para luego determinar si la suspensión del derecho de sufragio de conformidad con al artículo 16 número 2 de la Constitución Política de la República constituye un acto de discriminación y si esta solución se ajusta o no a las disposiciones internacionales contenidas en tratados ratificados por Chile y que se encuentran vigentes en nuestro ordenamiento.

Diversas razones justifican que las personas privadas de libertad no puedan ejercer este derecho. En primer lugar, las personas se pueden ver privadas de este derecho como consecuencia de la comisión de un delito y comprobada su participación en él, se les sanciona con una pena de privación de libertad, conjuntamente con la privación o suspensión del derecho de sufragio.

Tal sanción se explica también porque las personas que han participado en alguna conducta delictiva, durante la investigación o el juicio respectivo, se las puede privar de la libertad como una medida preventiva a fin de asegurar el éxito de la investigación o para preservar la seguridad de la sociedad o de la víctima. En estas situaciones, antes de la dictación de la sentencia en el caso, las personas también podrán encontrarse en una situación de privación o, mejor dicho, de suspensión del derecho de sufragio. En este último caso, esto se explica por una razón más bien fáctica y no jurídica, en estricto rigor. Efectivamente, desde el punto de vista jurídico, el imputado goza de la presunción de inocencia, la cual forma parte del bloque constitucional de derechos humanos (Nogueira Alcalá, 2005: 221) y, por ende, al igual que cualquier otra persona, es titular del derecho humano de sufragio (Sentencia del Tribunal Constitucional rol 1.152-08, 2008). ${ }^{1}$ Vale decir, en estos casos la persona no puede ejercer este derecho debido a que, por ejemplo, el Estado no cuenta con los medios económicos o jurídicos para dar cumplimiento al deber de respetar y garantizar este derecho. En este último caso,

1. En esta sentencia se puede apreciar la discusión que ha generado esta materia y las opiniones opuestas en cuanto a si la presunción de inocencia se ve o no afectada por la aplicación del artículo 16 de la Constitución Política de la República. 
a su vez, el Estado puede no contar con una norma que regule el ejercicio del derecho de sufragar de personas privadas de libertad, pero, que no son responsables de delito alguno, o bien, la conducta sancionada no contempla la pena de privación del derecho de sufragio.

Tomando en consideración lo anterior es que en este trabajo se analizarán, de conformidad con el derecho internacional, los siguientes aspectos:

- Las modalidades de aplicación de esta sanción y las razones que justifican su aplicación a personas condenadas por un determinado delito.

- El carácter discriminatorio de la aplicación de la sanción de privación o suspensión del derecho a sufragio, tanto para personas condenadas por un delito como a aquellas que se encuentran privadas de libertad, pero que no tienen la calidad de condenadas.

- La responsabilidad internacional del Estado.

- La necesidad de una reforma constitucional.

\section{Modalidades de aplicación de esta sanción y las razones que justifican su aplicación a personas condenadas por un determinado delito}

A fin de poder comprender de la mejor manera posible si la aplicación de esta sanción puede o no constituir un acto de discriminación por parte de un Estado, vulnerando sus obligaciones internacionales, se mencionarán brevemente diversas modalidades de aplicación de esta sanción de privación o suspensión del derecho de sufragio, así como las razones que se han esgrimido para su justificación. Estos aspectos pueden permitir apreciar el efecto que puede llegar a tener esta sanción en la vida de una persona y, por lo tanto, sopesar con mayor claridad la utilidad y justificación de la misma en relación con otros aspectos relacionados con este tema, como la rehabilitación de la persona privada de libertad y el eventual carácter discriminatorio de dicha sanción.

\section{Modalidades}

La privación o suspensión de este derecho se puede aplicar de la siguiente manera (Dhami, 2009: 123):

- Una persona podrá no ejercer este derecho por un determinado número de años. En este caso, la privación de este derecho corresponderá a los años de la respectiva condena, o incluso algunos años después de cumplida la pena.

- Esta sanción se podrá aplicar para todo tipo de delitos o solo respecto de determinados delitos de especial gravedad para la sociedad.

- Por otro lado, se puede consagrar positivamente que se suspende este derecho sólo respecto de personas condenadas o bien respecto de personas acusadas, como es el caso de Chile. 
- También una persona se puede ver privada de este derecho por el sólo hecho de encontrarse privada de libertad, sin tener la calidad de imputado, ni menos condenado, sino por la aplicación de una medida de carácter cautelar o de apremio.

\section{Razones en pro y en contra de consagrar una privación} o suspensión del derecho de sufragio

Los argumentos a favor y en contra para consagrar la privación o suspensión del derecho a sufragio son los siguientes (Barrientos, 2011: 255; Dhami, 2009: 126):

a) Los argumentos que se han esgrimido a favor de este tipo de sanciones consisten fundamentalmente en:

- Incumplimiento del contrato social por haber delinquido.

- Posibilidad de que las personas que han infringido la ley puedan corromper el proceso electoral o cometer fraude electoral.

- Fomentar la responsabilidad cívica y el respeto al imperio de la ley.

- Prevenir la comisión de nuevos delitos.

- Resulta costoso y genera problemas prácticos el ejercicio del derecho de sufragio por parte de personas privadas de libertad.

b) Razones en contra de la privación o suspensión del derecho de sufragio :

- No existe evidencia que permita sostener que la aplicación de esta sanción efectivamente pueda disuadir a no cometer delitos.

- No contribuye a la rehabilitación de la persona.

- La obligación de cumplir la ley está estrechamente vinculada al ejercicio del derecho de sufragio, en la medida que permite a las personas participar en el proceso de elaboración de la ley.

\section{Críticas a estos argumentos}

Ante el argumento que sostiene que no se debe aplicar esta sanción ya que su aplicación socavaría el imperio de la ley al no permitir a determinados ciudadanos participar en el proceso de elaboración y aprobación de la ley, lo cierto es que toda persona antes de cometer un delito ha participado, al menos indirectamente, en el proceso de elaboración de la ley y ello no ha sido suficiente para disuadirlo de no vulnerarla. A su vez, este es un argumento en extremo idealista porque, en la práctica, la participación de los ciudadanos en el proceso de elaboración de las leyes es muy indirecta. Esta participación se limita simplemente a la elección de los miembros del poder legislativo. Eventualmente, se podrá participar de manera más directa en dicho proceso en el caso de que una persona sea invitada a intervenir en las comisiones respectivas del Senado o la Cámara 
de Diputados en que se discutan los proyectos de ley, dando su opinión o proponiendo ideas o cambios al proyecto que se discute.

Con respecto al argumento que sostiene que las personas condenadas o privadas de libertad pueden corromper el sistema electoral o cometer fraude electoral, es sabido que ello no es privativo de tales personas. La historia está plagada de ejemplos de votaciones afectadas por fraudes electorales realizados por personas no privadas de libertad. Incluso se podría sostener lo contrario, en el sentido de que privar del voto a estas personas puede ser una forma de corrupción o fraude al proceso de elección. Efectivamente, si bien se debe partir de la presunción de buena fe de los actos de las personas y del propio Estado, lo cierto es que la privación del derecho de sufragio puede afectar profundamente un proceso democrático o el Estado de derecho, y por tanto, alterar drásticamente el resultado de una elección.

Como ejemplo de lo anterior, cabe mencionar que «la elección presidencial de Estados Unidos del año 2000, en la que G. W. Bush ganó por 537 votos, pudo haber sido determinada por la prohibición permanente del derecho a sufragio de más de 400.000 excriminales en el Estado de Florida» (Dhami, 2009: 133). Se ha sostenido esto porque las poblaciones penitenciaras mayoritariamente son de pensamiento o tendencia liberal, por lo tanto, estos grupos son propensos a votar por liberales o demócratas en lugar de conservadores o republicanos (Dhami, 2009: 132). De esta manera era previsible que, si dicha población penitenciaria hubiese podido ejercer su derecho a sufragar, probablemente hubiera ganado el candidato liberal o demócrata y no el conservador o republicano, con todas las consecuencias políticas e internacionales que ello puede generar.

En este mismo orden de ideas, cabría la posibilidad de que se utilice fraudulentamente la norma contenida en el artículo 16 número 2 de la Constitución Política de la República, por ejemplo, al interponer una querella por un delito que merezca pena aflictiva en contra de un potencial contrincante político con posibilidades de ganar una elección para «sacarlo» del camino o de la carrera política, ya que basta con tener la calidad de «acusado de..» para verse afectado con la privación del derecho de sufragio, tanto activo como pasivo. Esta situación hipotética nos muestra la necesidad de reformar tal norma, sin perjuicio de la razón jurídica de fondo que justifica tal reforma, que no es otra que la vulneración de la presunción de inocencia y el carácter discriminatorio de esta sanción así consagrada en el artículo antes mencionado del texto constitucional, aspectos que se analizarán a continuación.

\section{El carácter discriminatorio de la privación o suspensión del derecho a sufragio}

\section{Razones extrajurídicas}

La privación o suspensión del derecho de sufragio puede ser considerado violatorio del derecho a no ser discriminado. Al respecto se recurrirá a la noción de discriminación que se ha desarrollado en el ámbito de Naciones Unidas por el Comité de Derechos 
Humanos, en la medida que es la que se utiliza a nivel universal y sirve de orientación a los textos multilaterales de derechos humanos. Dicho Comité, en su calidad de órgano de supervisión del Pacto Internacional de Derechos Civiles y Políticos, ha definido la discriminación señalando que:

debe entenderse referida a toda distinción, exclusión, restricción o preferencia que se base en determinados motivos, como la raza, el color, el sexo, el idioma, la religión, la opinión política, o de otra índole, el origen nacional o social, la posición económica, el nacimiento o cualquier otra condición social, y que tenga por objeto o por resultado anular o menoscabar el reconocimiento, goce o ejercicio, en condiciones de igualdad, de los derechos y libertades fundamentales de todas las personas (Instituto de Nacional de Derechos Humanos, 2014: 31).

Teniendo a la vista este concepto de discriminación, se pueden apreciar algunos datos estadísticos que podrían dar cuenta de una relación entre una de las razones de discriminación, como es el racismo, y la privación del derecho a sufragio. En este sentido, se ha afirmado que:

las leyes de privación del sufragio pueden llevar a la desigualdad..., en Estados Unidos es evidente que hay una tasa desproporcionada de condena y encarcelamiento de los afroamericanos. Por ejemplo, en 2003 los reclusos negros de sexo masculino representaban aproximadamente el $44 \%$ de todos los reclusos con pena de un año o más, mientras que los reclusos blancos representaban el 35\% (Dhami, 2009: 129).

Por su parte, se ha afirmado que «los Estados con mayor población penitenciaria no blanca fueron más propensos a privar a los criminales condenados que los Estados con proporciones menores de presos no blancos, y estas políticas de privación tienden a ser más restrictivas» (Dhami, 2009: 130).

A su vez, se puede sostener que esta sanción o pena pueda ser discriminatoria porque «la mayoría de los delincuentes son pobres o de clase trabajadora y... en muchos países hay un número desproporcionado de minorías étnicas representadas en sus filas» (Dhami, 2009: 132). Es a ellos a quienes se les priva del derecho de sufragio. De conformidad con lo antes señalado es que se ha llegado a sostener la posibilidad de que exista una «relación entre racismo y el desarrollo de leyes de privación del sufragio a criminales en los Estados Unidos» (Dhami, 2009: 129).

En Chile también se puede apreciar que la población penitenciara es mayoritariamente de un origen social bajo, o con escaso nivel de escolaridad. Así, por ejemplo, según un estudio del año 2007 del Ministerio de Planificación, la población penal, en relación al grado de escolaridad, era la siguiente: analfabeto, 4\%; educación básica incompleta, $43 \%$; educación básica completa, $17 \%$; educación media incompleta, $23 \%$; educación media completa, $11 \%$; educación universitaria incompleta, $1 \%$; educación universitaria completa, 1\% (Gobierno de Chile, Ministerio de Planificación, 2007).

Actualmente, el número de reclusos en el régimen subsistema cerrado son 50.628; en el subsistema abierto 60.601; y en el régimen de control semiabierto: 697 (Gobierno 
de Chile, Gendarmería de Chile, 2017). Por lo tanto, es un elevado número de personas las que se ven vulneradas en su derecho de sufragio y eventualmente en la vulneración del principio de inocencia. A su vez, y en la medida que la privación o suspensión de derecho de sufragio afecta a este tipo de personas con escaso nivel académico y, generalmente, de escasos recursos económico, se convierte en una sanción discriminatoria que contribuye a la segregación social y a mantener a esas personas en un mundo de marginados y, por ende, discriminados.

Ahora bien, es posible sostener que la sanción per se no es discriminatoria ya que la ley, y en este caso la ley que contemple esta sanción, es general y abstracta. En este sentido teórico, la ley no puede ser discriminatoria. En otras palabras, al consagrase en la ley penal un delito con la respectiva pena, incluyendo la sanción de privación o suspensión del derecho de sufragio, no se consagra tal tipo penal para afectar solamente a la población de escasos recursos económicos o de bajo nivel académico. La ley se aplica a todo aquel que cometa un delito determinado.

Sin embargo, lo anterior resulta altamente cuestionable si se tiene presente lo que comúnmente se suele afirmar en el sentido de que la persona que roba una gallina termina en la cárcel y los «ladrones de cuello y corbata», que cometen generalmente delitos financieros de alto monto, quedan libres o simplemente deben pagar una determinada indemnización. El pobre y con poca educación termina en la cárcel, la persona con mejores recursos económicos y mayor nivel académico, queda libre. En otras palabras, lo que se quiere destacar es que «se puede dar el caso en que los prejuicios arraigados de un individuo [o de una comunidad] contra un grupo específico... promuevan la adopción de normas o políticas discriminatorias» (Centro de Documentación de Honduras). Precisamente, la situación antes mencionada se puede reflejar en la consagración de la privación o suspensión del derecho de sufragio, como una sanción conexa a la privación de libertad por la comisión de un delito.

Junto con los aspectos fácticos y sociológicos antes mencionados, que dan cuenta del carácter discriminatorio de la sanción de privación o suspensión del derecho de sufragio, dicha sanción también puede calificarse de discriminatoria, ahora por consideraciones jurídicas en la medida que se aplique a personas acusadas y no condenadas por un delito, por las razones que se analizarán en el punto siguiente.

\section{Razones jurídicas que explican el carácter discriminatorio de la sanción}

El artículo 16 número 2 de la Constitución Política de la República dispone que el derecho a sufragio se suspende por «hallarse la persona acusada por delito que merezca pena aflictiva o por delito que la ley califique como conducta terrorista», y a su vez, otras normas constitucionales establecen como requisitos para optar a cargos públicos de elección popular (Presidente de la República, senador, diputado) el ser ciudadano con derecho a sufragio, misma exigencia contenida en la Ley Orgánica Constitucional de Municipalidades para ser electo alcalde o concejal, y en la Ley Orgánica Constitucional sobre Gobierno y Administración Regional para ser electo consejero regional. 
Como se puede apreciar, la suspensión del derecho a sufragio en los términos del artículo 16 número 2 de la Constitución no sólo impide el ejercicio de un derecho fundamental político básico, como es el derecho a elegir representantes en el parlamento y otras autoridades republicanas, sino que también impide optar a ocupar dichos cargos, a pesar de no estar acreditada la responsabilidad penal de ese ciudadano o ciudadana.

Esta es la solución constitucional chilena. La pregunta que nos corresponde plantear y responder es si esta solución es coherente con el sistema regional de defensa de derechos humanos del que es parte Chile.

La Convención Americana de Derechos Humanos, también conocida como Pacto de San José de Costa Rica (Decreto 873, 1991) consagra en su artículo 23 número 1 una serie de derechos de naturaleza política, dentro de los cuales se encuentra el derecho de «votar y ser elegidos en elecciones periódicas auténticas, realizadas por sufragio universal e igual y por voto secreto que garantice la libertad de expresión de la voluntad de los electores». En el número 2 de la misma disposición expresamente se señala que «la ley puede reglamentar el ejercicio de los derechos y oportunidades a que se refiere el inciso anterior, exclusivamente por razones de edad, nacionalidad, residencia, idioma, instrucción, capacidad civil o mental, o condena, por juez competente, en proceso penal».

Por su parte, la Corte Interamericana de Derechos Humanos ha tenido la oportunidad de pronunciarse sobre la importancia del derecho de sufragio tanto como derecho fundamental autónomo como en su calidad de instrumento para el desarrollo exitoso del proceso democrático. Es así como en el caso Yatama contra Nicaragua la Corte ha señalado expresamente que resulta «indispensable que el Estado genere las condiciones y mecanismos óptimos para que dichos derechos políticos puedan ser ejercidos en forma efectiva, respetando el principio de igualdad y no discriminación» (Corte Interamericana de Derechos Humanos, 23 de junio de 2005: párrafo 195), pues «el ejercicio de los derechos a ser elegido y a votar, íntimamente ligados entre sí, es la expresión de las dimensiones individual y social de la participación política» (Corte Interamericana de Derechos Humanos, 23 de junio de 2005: párrafo 197). En consecuencia, «el derecho al voto es uno de los elementos esenciales para la existencia de la democracia y una de las formas en que los ciudadanos ejercen el derecho a la participación política» (Corte Interamericana de Derechos Humanos, 23 de junio de 2005: párrafo 198).

Siguiendo esta misma línea, en el caso Castañeda Gutsman contra Estados Unidos Mexicanos la Corte ha sostenido que «los ciudadanos tienen el derecho de participar activamente en la dirección de los asuntos públicos directamente mediante referendos, plebiscitos o consultas o bien, por medio de representantes libremente elegidos. El derecho al voto es uno de los elementos esenciales para la existencia de la democracia y una de las formas en que los ciudadanos expresan libremente su voluntad y ejercen el derecho a la participación política» (Corte Interamericana de Derechos Humanos, 6 de agosto de 2008: párrafo 147).

Tal como se puede apreciar, tanto de la lectura del artículo 23 de la Convención como de la jurisprudencia de la Corte Interamericana de Derechos Humanos citada, se desprende con meridiana claridad que el derecho a sufragio, en sus dos dimensiones, 
es un derecho fundamental esencial para la democracia y que no puede ser restringido sino por causales sumamente graves y expresamente contempladas en la ley. Y en este sentido, el artículo 2 de la misma Convención dispone la obligación de los Estados partes de «adoptar, con arreglo a sus procedimientos constitucionales y a las disposiciones de esta Convención, las medidas legislativas o de otro carácter que fueren necesarias para hacer efectivos» los derechos y libertades consagrados en la misma, dentro de los que se encuentran estos derechos políticos, como el derecho sufragio.

La misma Corte Interamericana de Derechos Humanos, en el caso López Mendoza contra Venezuela (Corte Interamericana de Derechos Humanos, 1 de septiembre de 2011: párrafo 101), ha señalado expresamente que el artículo 23 número 2 de la Convención determina cuáles son las causales que permiten restringir los derechos reconocidos en el artículo 23 número 1, así como, en su caso, los requisitos que deben cumplirse para que proceda tal restricción. En dicho caso, que se refería a una restricción impuesta por vía de sanción, la condena debía ser dictada por juez competente, en un proceso penal. Sin embargo, ninguno de esos requisitos se cumplió, pues el órgano que impuso dichas sanciones no era un juez competente, no hubo condena y las sanciones no se aplicaron como resultado de un proceso penal, en el que tendrían que haberse respetado las garantías judiciales consagradas en el artículo 8 de la Convención Americana de Derecho Humanos

En consecuencia, si bien la Corte Interamericana de Derechos Humanos no se ha pronunciado directamente sobre la suspensión del derecho a sufragio en su perspectiva activa y pasiva en el caso de las personas que se encuentran sometidas a un proceso penal inconcluso (Convención Americana sobre Derechos Humanos,2013: 562), no podemos sino concluir, a la luz del artículo 23 número 2 de la Convención y de la importancia que este organismo jurisdiccional reconoce a los derechos políticos en el seno de una democracia, que la solución contemplada en el artículo 16 número 2 de la Constitución chilena es contradictoria con el Pacto de San José de Costa Rica, toda vez que impone como sanción la suspensión de un derecho fundamental básico, como es el ejercicio del derecho a sufragio, a una persona que aún no ha sido condenada penalmente, única hipótesis en relación a este punto considerada por el mismo Pacto.

Por su parte, el Pacto Internacional de Derechos Civiles y Políticos, adoptado por la Asamblea General de Naciones Unidas en el año 1966 (Decreto 778, 1989) establece en su artículo 25 que «todos los ciudadanos gozarán, sin ninguna de las distinciones mencionadas en el artículo 2, y sin restricciones indebidas, de los siguientes derechos y oportunidades», dentro del cuales se encuentra el derecho a "votar y ser elegido en elecciones periódicas, auténticas, realizadas por sufragio universal e igual y por voto secreto que garantice la libre expresión de la voluntad de los electores». Norma que a su vez debe ser relacionada con la disposición contenida en el artículo 14 número 2 del mismo instrumento, el que dispone que «toda persona acusada de un delito tiene derecho a que se presuma su inocencia mientras no se pruebe su culpabilidad en conformidad a la ley». De esta forma, la solución constitucional chilena es también contradictoria con el Pacto Internacional de Derechos Civiles y Políticos, pues niega el 
ejercicio de un derecho político como sanción a una persona que aún no ha sido declarada culpable de conformidad a la ley.

En el año 1996, el Comité de Derechos Humanos de Naciones Unidas señaló expresamente, en relación con los derechos políticos, que:

no se permite hacer distinción alguna entre los ciudadanos en lo concerniente al goce de esos derechos por motivos de raza, color, sexo, idioma, religión, opiniones políticas o de cualquier otra índole, origen nacional o social, posición económica, nacimiento o cualquier otra condición social (Comité de Derechos Humanos, 1996: apartado 3).

El mismo documento explicita:

los motivos para privarles de ese derecho deben ser objetivos y razonables. Si el motivo para suspender el derecho a votar es la condena por un delito, el período de tal suspensión debe guardar la debida proporción con el delito y la condena. A las personas a quienes se prive de libertad pero que no hayan sido condenadas no se les debe impedir que ejerzan su derecho a votar (Comité de Derechos Humanos, 1996: apartado 14).

Por su parte, en el año 2007 la Comisión Interamericana de Derechos Humanos, en el documento denominado «Principios y buenas prácticas sobre la protección de las personas privadas de libertad en las Américas», sostuvo que:

toda persona privada de libertad será igual ante la ley, y tendrá derecho a igual protección de la ley y de los tribunales de justicia. Tendrá derecho, además, a conservar sus garantías fundamentales y ejercer sus derechos, a excepción de aquéllos cuyo ejercicio esté limitado o restringido temporalmente, por disposición de la ley, y por razones inherentes a su condición de personas privadas de libertad (Comisión Interamericana de Derechos Humanos, 2008: 2).

En consecuencia, la norma del artículo 16 de la Constitución Política de la República vulnera, además del ejercicio de derechos fundamentales de naturaleza política, el principio de inocencia, que se manifiesta en la Constitución en relación con la noción de debido proceso (Barrientos, 2011: 259). Esta norma, al privar del derecho de sufragio a personas que son inocentes (se es inocente mientras no se pruebe lo contrario), es discriminatoria, ya que las demás personas no acusadas y que son igualmente inocentes sí pueden votar.

La gravedad de este problema jurídico en Chile no se limita a lo anterior. Efectivamente, las personas que ni siquiera tiene la calidad de «acusadas de», siguiendo la terminología de nuestro texto constitucional, pero que se encuentren privadas de libertad como consecuencia de la aplicación de una medida cautelar o de apremio, no pueden ejercer el derecho de sufragio. En este sentido, la regla general debe ser que, de conformidad a lo señalado por la propia Corte Interamericana de Derechos Humanos, «las personas privadas de libertad, pero que no hayan sido condenadas aún, jamás deben ser privadas de sus derechos políticos» (Human Rights Foundation, 2011: 6). 
En definitiva, la suspensión del derecho de sufragio por estar la persona acusada penalmente constituye una limitación constitucional al ejercicio de un derecho fundamental, que se convierte en buenas cuentas en la aplicación de una sanción penal anticipada. De esta manera se vulnera no sólo el principio de presunción de inocencia, sino todo el sistema de reconocimiento de derechos políticos consagrado en la Convención Americana de Derechos Humanos y el Pacto Internacional de Derechos Civiles y Políticos, cuyo contenido resulta obligatorio para Chile a la luz de las normas del derecho internacional público, y especialmente el artículo 5 inciso segundo de la misma Carta Fundamental. Por lo mismo, como lo destaca la literatura especializada:

La solución que provee la norma externa, en este caso, debe primar no sólo porque emana de un tratado que el Estado debe honrar, sin desvirtuar su finalidad y objeto, o porque el Estado (y todos sus órganos, cualquiera sea su carácter) tiene la obligación internacional de adoptar medidas efectivas para asegurar y proteger los derechos, sino porque el precepto permite arribar a la mejor solución posible considerados todos los niveles y aspectos de la cuestión debatida. En ningún caso debe olvidarse que los Estados tienen la obligación de velar por la plena protección de los derechos, y por plena protección entiendo también la mejor protección disponible (Barrientos, 2011: 314).

\section{Responsabilidad internacional del Estado}

Conforme a lo antes desarrollado, se debe resaltar una cuestión fundamental, esto es, que Chile está obligado por un expreso mandato constitucional, contenido en el artículo 5 inciso segundo de la Constitución Política de la República, a cumplir con los tratados de derechos humanos. ${ }^{2}$ Conforme a dicho mandato y a la luz de los artículos 1 y 2 del Pacto de San José (similares a las contenidas en los artículos 2 y 3 del Pacto Internacional de Derechos Civiles y Políticos), el Estado de Chile ha asumido como obligaciones generales y esenciales: la obligación de respetar y garantizar los derechos y libertades reconocidos en dicho tratado, así como su libre y pleno ejercicio a toda persona sin discriminación alguna y la obligación de adoptar, con arreglo a sus procedimientos constitucionales y las disposiciones de la Convención Americana sobre Derechos Humanos, las medidas legislativas o de otro carácter que fueren necesarias para hacer efectivos tales derechos y libertades.

En relación con las dos obligaciones antes mencionadas, se debe precisar que los Estados parte del Pacto de San José, entre ellos Chile, no sólo han asumido la obligación general de no discriminar, sino que «la ausencia de políticas estatales o de leyes aprobadas, no puede utilizarse como excusa para discriminar a otros» (Centro de Documentación de Honduras: 3). Como ha dicho la Corte Interamericana de Derechos Humanos:

2. Artículo 5 inciso segundo de la Constitución Política de la República: «El ejercicio de la soberanía reconoce como limitación el respeto a los derechos esenciales que emanan de la naturaleza humana. Es deber de los órganos del Estado respetar y promover tales derechos, garantizados por esta Constitución, así como por los tratados internacionales ratificados por Chile y que se encuentren vigentes». 
La obligación de garantizar el libre y pleno ejercicio de los derechos humanos no se agota con la existencia de un orden normativo dirigido a hacer posible el cumplimiento de esta obligación, sino que comporta la necesidad de una conducta gubernamental que asegure la existencia, en la realidad, de una eficaz garantía del libre y pleno ejercicio de los derechos (Corte Interamericana de Derechos Humanos, 29 de julio de 1988: párrafo 167).

Por su parte, la Corte Europea de Derechos humanos ha declarado que una legislación electoral, de un Estado parte, redactada en términos poco precisos o que en términos generales priva del derecho de sufragio a personas privadas de libertad, viola el artículo 3 del Protocolo 1 de la Convención Europea de Derechos Humanos (Tribunal Europeo de Derechos Humanos, 12 de agosto de 2014: párrafo 14). ${ }^{3}$ En otras palabras, «la responsabilidad internacional deriva del incumplimiento de una obligación primaria, esto es, de la obligación general de respeto y garantía de los derechos humanos por parte de los Estados» (Del Toro Huerta, 2002: 668). En este mismo sentido se puede entender que se sostenga que «ningún Estado puede invocar dificultades o deficiencias de derecho interno como excusa para evadirse de sus obligaciones internacionales» (Cançado Trindade, 2002: 301). Incluso más, esta responsabilidad internacional encuentra:

su fundamento último en el derecho internacional general, en particular, en la noción de principios generales del derecho, concepto al que la Corte [Internacional de Justicia] ha dado un contenido nuevo al entender por ellos no sólo aquellos que han sido extraídos de los ordenamientos internos sino, también, los que existen y operan en el derecho internacional independientemente de la práctica y que son fruto del consenso de los Estados al respecto... (De Ory Arriagada, 2005: 451).

A su vez, Chile, de conformidad con los artículos 8 número 2 del Pacto de San José y 14 número 2 del Pacto Internacional de Derechos Civiles y Políticos, ha contraído la obligación de reconocer que toda persona inculpada de un delito tiene derecho a que se presuma su inocencia mientras no se establezca legalmente su culpabilidad. Por otra parte, en virtud del artículo 27 del Pacto de San José el Estado de Chile no puede suspender diversos derechos, entre ellos, los derechos políticos.

De esta manera, Chile, en virtud del artículo 16 de su Constitución Política de la República, vulnera los dos tratados antes mencionados en una triple dimensión: vulnera el derecho a no ser discriminado por las razones ya señaladas, vulnera el principio de inocencia y suspende un derecho no teniendo facultad para hacerlo.

Los aspectos antes señalados pueden generar responsabilidad internacional del Estado, al ser denunciado ante un órgano internacional, como la Comisión Interamericana de Derechos Humanos o el Comité de Derechos Humanos de las Naciones Unidas.

3. El artículo 3 de dicho Protocolo señala: «Derecho a elecciones libres. Las Altas Partes Contratantes se comprometen a organizar, a intervalos razonables, elecciones libres con escrutinio secreto, en condiciones que garanticen la libre expresión de la opinión del pueblo en la elección del cuerpo legislativo». 
Esta responsabilidad internacional se basa, además de las razones ya mencionadas, en que nuestro país ha vulnerado de manera constante, sistemática y generalizada el derecho de sufragio. Efectivamente, Chile ratificó el Pacto de San José el 10 de agosto de 1990, y el Pacto Internacional de Derechos Civiles y Políticos ha estado vigente en el derecho nacional desde el año 1989. Estos tratados, al ratificarse e incorporarse al ordenamiento jurídico nacional, se transforman en derecho chileno, por lo tanto, en preceptos jurídicos que deben ser cumplidos como cualquier otra norma jurídica nacional. De esta manera, durante los últimos 25 años Chile ha violado diversas disposiciones de derecho internacional, en particular los artículos ya mencionados.

La relevancia y complejidad de las obligaciones internacionales antes señaladas que ha adquirido el Estado de Chile no sólo radica en el contenido de dichas reglas jurídicas, sino en que, además, éstas deben interpretarse de conformidad con el principio pro homine, consagrado, entre otras disposiciones internacionales, en el artículo 5 del Pacto Internacional de Derechos Civiles y Políticos, en el sentido de que:

i) Ninguna disposición del presente Pacto podrá ser interpretada en el sentido de conceder derecho alguno a un Estado, grupo o individuo para emprender actividades o realizar actos encaminados a la vulneración de cualquiera de los derechos y libertades reconocidos en el Pacto o a su limitación en mayor medida que la prevista en él.

ii) No podrá admitirse restricción o menoscabo de ninguno de los derechos humanos fundamentales reconocidos o vigentes en un Estado parte en virtud de leyes, convenciones, reglamentos o costumbres, so pretexto de que el presente Pacto no los reconoce o los reconoce en menor grado.

\section{Necesidad de una reforma al texto constitucional}

La situación en que el artículo 16 número 2 de la Constitución Política de la República deja al Estado de Chile en relación con el cumplimiento de sus obligaciones internacionales en materia de derechos humanos no sólo ha sido denunciada por la doctrina, también ha sido asumida por algunos legisladores que han intentado remediarla.

En el año 2007 fue presentado un proyecto de reforma constitucional que perseguía derogar el artículo 16 número 2 de la Constitución (Congreso Nacional de Chile, 2007) ${ }^{4}$ fundándose entre otras razones en que:

establecido el hecho de que la suspensión del derecho a sufragio constituye una pena; y que es una pena objetiva aplicada sin haberse establecido la culpabilidad del sujeto procesado o acusado, devenida de un acto procesal, la acusación, y no de un acto jurisdiccional, como es la sentencia, es prístina la conclusión: la norma del artículo 16 número 2 de la Constitución Política de la República constituye una violación de la presunción de inocencia, principio que protege la situación jurídica de inocencia de la persona durante todo el procedimiento penal, mientras no se produzca prueba concreta capaz de generar el grado de certeza necesario para establecer la participación

4. En la actualidad el texto del proyecto de reforma constitucional se encuentra archivado. 
criminal y la culpabilidad, inherentes a una sentencia condenatoria firme (Congreso Nacional de Chile, 2007: párrafo 9).

Este principio además se encuentra «recogido en el Pacto Internacional de Derechos Civiles y Políticos (artículo 14 número 2) y en la Convención Americana de Derechos Humanos (artículo 8 número 2). Ambos textos, vigentes en Chile y enarbolados a nivel constitucional» (Congreso Nacional de Chile, 2007: párrafo 9).

En el año 2011 se presentó otro proyecto de reforma constitucional que buscaba permitir el ejercicio del derecho de sufragio a las personas privadas de su libertad y que no han sido condenadas a pena aflictiva (Congreso Nacional de Chile, 2011), ${ }^{5}$ fundándose en razones de igualdad ante la ley, de reinserción social y coherencia con el sistema americano de protección a los derechos humanos.

Conforme a estas últimas razones, en relación con los demás aspectos desarrollados en el presente trabajo, no cabe duda de que el texto constitucional actual requiere de una reforma que recoja los criterios antes explicados. De esta manera, el Estado de Chile no solo dejará de vulnerar los derechos fundamentales de las personas en esta materia, sino que, además, se pondrá término a la vulneración de los tratados internacionales que regulan el derecho de sufragio y a su eventual responsabilidad internacional.

\section{Conclusiones}

Independientemente de que se pueda estar a favor o en contra de la aplicación de la privación o suspensión del derecho de sufragio, se puede concluir lo siguiente.

La Constitución Política de la República Chile sufre de una grave contradicción en su propio texto al suspender un derecho político, el de sufragar, a una persona acusada de un delito que merezca pena aflictiva o que la ley califique de terrorista, ya que contradice el principio de inocencia que inspira y orienta todo ordenamiento jurídico, incluido el nuestro. De esta manera, se priva a una persona de la titularidad de un derecho, que en estricto rigor nunca ha perdido, ya que toda persona privada de libertad no condenada goza de la presunción de inocencia y, por lo tanto, es titular del derecho de sufragio como todo individuo en su calidad de ciudadano.

Como consecuencia de lo anterior, el Estado de Chile viola de manera constante, sistemática y generalizada el Pacto de San José en sus artículos 23, 29, 1 y 2, 8 número 2, así como los artículos 2, 3 y 14 párrafo 2 del Pacto Internacional de Derechos Civiles y Políticos. A su vez, al estar el Estado de Chile obligado a cumplir dichos tratados no sólo en virtud de las reglas propias del derecho internacional, sino por mandato de su propia Constitución a través de su artículo 5 inciso 2, se está vulnerando en la misma medida el propio texto constitucional.

De esta manera se podrá reclamar la responsabilidad del Estado ante órganos inter-

5. El proyecto de reforma constitucional se encuentra desarchivado desde el 15 de abril de 2015 . 
nacionales como también antes los respectivos órganos nacionales, especialmente los tribunales ordinarios de justicia y particularmente el Tribunal Constitucional.

Se puede garantizar el ejercicio de este derecho mediante un acto administrativo, no siendo necesario una ley para ello, al igual como se hizo por parte del Estado de Chile al regular el derecho de consulta de los pueblos indígenas. Bastará un decreto supremo que regule esta materia, sin perjuicio de que sea conveniente regularlo por ley, de manera que su regulación no quede entregada a un acto meramente administrativo.

Chile debe reformar su Constitución Política, en su artículo 16, y demás normas pertinentes, consagrando por ejemplo que, en vez de «acusados por» se diga «condenados por», o bien, consagrar que las personas no se verán privadas de sus derechos políticos, ni aún en caso de condena. En este último caso se genera un problema práctico en el sentido de que se limitará el derecho de sufragio de manera que la persona sólo podrá ejercer el derecho de votar, pero no podrá ser elegido.

Esta es una materia cuya correcta solución permitiría de una vez por todas fortalecer poco a poco las políticas penitenciarias de rehabilitación de las personas condenas por algún crimen o delito, especialmente si se tiene en cuenta que:

Las elecciones enfatizan que todos somos miembros de una comunidad, trabajando para un bien común, y que tenemos vínculos sociales. La votación representa una forma de crear y mantener esos lazos. Por lo tanto, psicológicamente y socialmente, el derecho a voto podría permitir a los presos percibirse a sí mismos como útiles, responsables, confiables y como ciudadanos respetuosos de la ley (Dhami, 2009: 131).

Si bien ese es un criterio que puede parecer utópico, como señalamos anteriormente, no es menos cierto que privar o suspender el derecho de sufragio a las personas privadas de libertad, y particularmente a las personas que no tienen la calidad de condenadas o imputadas por un crimen o delito, es un verdadero estigma que las discrimina y no contribuye a su rehabilitación.

\section{Referencias}

BARRIENTOS, Ignacio (2011). «Suspensión del derecho de sufragio por acusación penal. Vulneración constitucional de la presunción de inocencia». Estudios Constitucionales, 9 (2): 249-328.

Cançado Trindade, Antonio (2002). El derecho internacional de los derechos humanos en el siglo XXI. Santiago: Jurídica.

Cea Egaña, José Luis (2002). Derecho Constitucional Chileno. Tomo 1. Santiago: Ediciones Universidad Católica de Chile.

De Ory Arriagada, Carlos (2005). «La Corte Internacional de Justicia y los derechos humanos». En Ana Salinas de Frías y Marina Vargas Gómez-Urrutia (coordinadoras), Soberanía del Estado y derecho internacional. Homenaje al profesor Juan Antonio Carrillo Salcedo. Sevilla: Universidad de Córdoba, Universidad de Sevilla, Universidad de Málaga. 
Del Toro Huerta, Mauricio Iván (2002). «La responsabilidad internacional del Estado en el marco del derecho internacional de los derechos humanos». En Ricardo Méndez Silva (coordinador), Derecho internacional de los derechos humanos. Memoria del VII Congreso Iberoamericano de Derecho Constitucional (México D.F., 12-15 de febrero de 2002). Serie Doctrina Jurídica, núm. 98. México: Instituto de Investigaciones Jurídicas, Universidad Nacional Autónoma de México.

Dнамі, Mandeep K. (2009). «La política de privación del sufragio a los presos: ¿Una amenaza para la democracia?». Revista de Derecho (Universidad Austral), 12 (2): 121-135.

García, Gonzalo, Pablo Contreras y Victoria Placencia (2014). Diccionario constitucional chileno. Santiago: Tribunal Constitucional de Chile.

Human Rights Foundation (2011). Corte Interamericana de Derechos Humanos, Caso 12.668, Leopoldo López Mendoza contra República Bolivariana de Venezuela. Escrito de amicus curiae. Disponible en http://bit.ly/2vojBZ8.

Nogueira Alcalá, Humberto (2005). «Consideraciones sobre el derecho fundamental a la presunción de inocencia». Ius et Praxis, 11 (1): 221-241.

Instituto de Derechos Humanos (2014). Comité de Derechos Humanos de Naciones Unidas. Observación General núm. 18 de 1989, en Instrumentos internacionales, observaciones y recomendaciones generales de derechos humanos sobre igualdad, no discriminación y grupos de especial protección.

Comité de Derechos Humanos de Naciones Unidas (1996). Observación General núm. 25, «La participación en los asuntos públicos y el derecho de voto (artículo 25)», 57. ${ }^{\circ}$ Período de Sesiones.

Comisión Interamericana de Derechos Humanos (2008). Resolución o1/o8 sobre «Principios y Buenas Prácticas sobre la Protección de las Personas Privadas de Libertad en las Américas».

Gobierno de Chile, Ministerio de Planificación (2007). División de planificación, estudios e inversión. Departamento de estudios. El funcionamiento de la cárcel como exclusión en Chile. Disponible en http://bit.ly/2v8HPN9.

Centro de Documentación de Honduras (s.f.). Nociones fundamentales sobre la discriminación. Unidad de Estudio para la Prevención de la Discriminación. Disponible en http://bit.ly/2vjjqDI.

Gobierno de Chile, Gendarmería de Chile (2017). Población atendida por Gendarmería de Chile. Información disponible en: http://www.gendarmeria.gob.cl/ img/estadisticas_cuadro_1.gif

Tribunal Constitucional de Chile, sentencia rol 1.152-o8, 2008, de 25 de junio de 2008.

Corte Interamericana de Derechos Humanos, 23 de junio de 2005. 


\section{Sobre los autores}

Karl-Andreas Müller Guzmán es Profesor de Derecho Internacional. Magister en Derecho con mención en Derecho Internacional de la Universidad de Chile, Magister en Ciencia Jurídica y Doctor en Derecho de la Pontificia Universidad Católica de Chile. Actualmente se desempeña como académico en la Escuela de Derecho de la Universidad Santo Tomás, sede de Viña del Mar. Su correo electrónico es kmuller@santotomas.cl.

Evelyn Vicencio Rojas es Profesora de Derecho Político e Introducción al Derecho y Derechos Fundamentales. Magister en Estudios Interdisciplinares de género por la Universidad de Salamanca, España. Actualmente se desempeña como académica en la Escuela de Derecho de la Universidad Santo Tomás, sede Viña del Mar. Su correo electrónico es evelynvicencioro@santotomas.cl. 
